J. Amer. Soc. Hort. Sci. 117(6):902-905. 1992.

\title{
Foliar Applications of Potassium Silicate Reduce Severity of Powdery Mildew on Cucumber, Muskmelon, and Zucchini Squash
}

\author{
Jim Menzies', Pat Bowen', and David Ehret ${ }^{1}$ \\ Research Station, Agriculture Canada, P. 0. Box 1000, Agassiz, B. C. V0M 1A0, Canada \\ Anthony D.M. Glass ${ }^{2}$ \\ Department of Botany, University of British Columbia, 6270 University Boulevard, Vancouver, \\ B.C. V6T 2B1, Canada \\ Additional index words. Cucumis sativus, C. melo, Cucurbita pepo, Sphaerotheca fuliginea, Erysiphe cichoracearum
}

\begin{abstract}
The effect of soluble potassium silicate applied to cucumber (Cucumis sativus L.), muskmelon (C. melo L.), and zucchini squash (Cucurbita pepo L.) on the severity of powdery mildew was examined. Application methods included amending nutrient solutions to a concentration of $1.7 \mathrm{~mm} \mathrm{Si}$ and foliar sprays containing $1.7,8.5,17$, and $34 \mathrm{~mm} \mathrm{Si}$. Untreated plants and plants sprayed with distilled water were used as controls. The leaves of all plants were inoculated with known concentrations of conidia of Sphaerotheca fuliginea (Schlecht.:Fr.) Poll. (cucumber and mu\&melon) or Erysiphe cichoracearum DC.: Merat (zucchini squash) 1 day after the sprays were applied. Inoculated leaves on plants receiving the Si-amended nutrient solution or foliar sprays of $\geq 17.0 \mathrm{~mm}$ Si developed fewer powdery mildew colonies than those on control plants. Results of a separate experiment that included a potassium spray, indicated that the active ingredient of the potassium silicate sprays appears to be $\mathrm{Si}$. Experiments to test the persistence of Si foliar sprays on cucumber demonstrated that a $17 \mathrm{~mm}$ Si spray applied 7 days before inoculation with $\mathrm{S}$. fuliginea reduced mildew colony formation.
\end{abstract}

Silicon has been reported to increase the disease resistance of both monocot and dicot plants. Negative correlations between the $\mathrm{Si}$ content of plant tissues and disease severity have been reported for blast (Pyriculuria oryzae Br.: Cav.) and sheath blight (Corticium sasakii Shiriai) of rice (Aleshin et al., 1986; Mathai et al., 1978; Volk et al., 1958) and powdery mildew diseases of barley (Erysiphe gruminis DC. f. sp. hordei Em. Marchal on Hordeum vulgare L.) (Jiang et al., 1989), wheat (E. graminis D.C. f. sp. tritici Em. Marchal on Triticum aestivum L.) (Leusch and Buchenauer, 1989), and cucumber ( $S$. fuliginea) (Menzies et al., 1991a).

Previous studies of $\mathrm{Si}$ effects on plant disease have involved root absorption of $\mathrm{Si}$ from either soil or soilless media. Although the amendment of soilless media with $\mathrm{Si}$ can be adapted to greenhouse and similar industries (Menzies et al., 1991a; Samuels et al., 1991b), large amounts of Si must be applied to soils to adequately control diseases. For example, basal dressings of 250 and $500 \mathrm{~kg}$ sodium silicate/ha were required to reduce sheath blight of rice (Mathai et al., 1978) and an equivalent of 4500 $\mathrm{kg} \mathrm{SiO}_{2} /$ ha was necessary to control powdery mildew of wheat (Leusch and Buchenauer, 1989). A reduction of the incidence of a wilt pathogen of cucumber requires the application of 2000 to $4000 \mathrm{~kg}$ calcium silicate/ha or 2250 to $4500 \mathrm{~kg}$ potassium silicate/ ha (Miyake and Takahashi, 1983b). Foliar application of $\mathrm{Si}$ to field plants is potentially a viable alternative to root-zone appli-

Received for publication 5 Nov. 1991. Accepted for publication 6 May 1992. Agassiz Research Station Contribution no. 440. We acknowlege the assistance of A.L. Samuels, D. Vianzon, C. Koch, and T. Helmer, the statistical advice of J. Hall, Research Station, Agriculture Canada, Vancouver, B.C., and the support of the B.C. Greenhouse Vegetable Research Council and the Science Council of B.C. Mention of a trademark or proprietary product does not imply endorsement of the products named or criticism of other products that may also be suitable. The cost of publishing this paper was defrayed in part by the payment of page charges. Under postal regulations, this paper therefore must be hereby marked advertisement solely to indicate this fact.

${ }^{1}$ Research Scientist.

${ }^{2}$ Professor. cation. This method of $\mathrm{Si}$ application to control disease has been reported only once, to our knowledge. Aleshin et al. (1986) applied sprays of sodium metasilicate (440 mg.liter $\left.{ }^{-1}\right)$ and 1-ethoxysilatran $\left(180 \mathrm{mg} \cdot \mathrm{liter}^{-1}\right)$ and reduced the degree of rice blast infestation on both resistant and susceptible rice cultivars.

The objective of our study was to determine the extent of control of powdery mildew diseases of cucumber, muskmelon, and zucchini squash achieved through foliar or root applications of soluble potassium silicate, and the duration of control that may be obtained with foliar applications.

\section{Materials and Methods}

Long English cucumber ('Corona'), muskmelon ('Earlisweet') and zucchini squash ('Select') were used in the experiments.

Effective Si concentrations for foliar application. Cucumber, muskmelon, and zucchini squash plants were grown from seed sown in rockwool cubes (Grodan, Roermond, Holland), arranged at random on three greenhouse benches. Eight randomly chosen plants of each species were watered as needed with a nutrient solution containing ( in $\mathrm{mm}$ ): $1.75 \mathrm{Si}, 13.0 \mathrm{NO}_{3}, 1.5$ $\mathrm{H}_{2} \mathrm{P} \mathrm{O}_{4}, 7.5 \mathrm{~K}, 3.5 \mathrm{Ca}, 1.0 \mathrm{Mg}$, and 1.0 to $1.5 \mathrm{SO}_{4}$; and (in нм) $18.8 \mathrm{Fe}, 5.5 \mathrm{Mn}, 0.9 \mathrm{Zn}, 0.2 \mathrm{Cu}, 18.1 \mathrm{~B}$, and $1.0 \mathrm{Mo}$, with a $\mathrm{pH}$ of 6.0. Silicon was added in the form of potassium silicate as product K6 (National Silicates Ltd., Toronto, Ont.). The remaining plants were watered with a solution ( $\mathrm{pH}$ 6.0) containing the same nutrients but without added potassium silicate (the $\mathrm{Si}$ and $\mathrm{K}$ contents of the solution were 0.05 and 7.0 $\mathrm{mM}$, respectively).

Foliar treatments were applied when cucumber and zucchini squash had two fully expanded leaves and muskmelon had three. Treatments included an untreated control, a distilled water spray (pH 5.5), and Si sprays of 1.7, 8.5 (not applied to the zucchini squash), and $17.0 \mathrm{~mm}$ (also containing $0.5,2.5$, and $5.0 \mathrm{~mm}$ $\mathrm{K}$, respectively). The $\mathrm{Si}$ sprays were prepared by diluting the appropriate amount of potassium silicate in distilled water and adjusting to $\mathrm{pH} 5.5$ with phosphoric acid. A drop of Tween 20 
surfactant was added to $500 \mathrm{ml}$ of all spray solutions. The foliar treatments were applied to runoff to the adaxial surface of leaf 2 of cucumber and zucchini squash and leaves 2 and 3 of muskmelon on seven to nine randomly selected plants that were not receiving the $1.75 \mathrm{~mm} \mathrm{Si}$ nutrient solution.

Twenty-four hours after the sprays were applied, sprayed leaves and corresponding leaves on unsprayed plants were inoculated with conidia of the appropriate powdery mildew pathogen. Conidia of $S$. fuliginea, which infects cucumber and muskmelon, and E. cichoracearum, which infects zucchini squash, were collected from naturally infected leaves of cucumber and zucchini squash, respectively. The fungi were identified using conidial characteristics (Boesewinkel, 1980). Source leaves were shaken $24 \mathrm{~h}$ before harvest of the conidia to dislodge old conidia and ensure a high viability of inoculum. The conidia were inoculated onto the adaxial surface of the leaves in an undiluted Fluorinert (FC-43; 3M Canada Inc., London, Ont.) (Menzies and MacNeill, 1986; Reeser et al., 1983) suspension of 2000 conidia/ml at a rate of $0.5 \mathrm{ml} / \mathrm{leaf}$. The inoculated plants were then incubated in the greenhouse for 7 to 10 days, when powdery mildew colonies became visible on the leaves. At this time the colonies on each inoculated leaf were counted. The colony counts from leaves 2 and 3 of the muskmelon plants were summed for data analysis. The experiment was repeated with the addition of a $34 \mathrm{~mm} \mathrm{Si}$ spray on all plant species and an $8.5 \mathrm{~mm} \mathrm{Si}$ spray treatment applied to zucchini squash.

The data were analyzed using analysis of variance (ANOVA; SAS, 1985) and Dunnett's test for multiple comparisons among treatments and a control (Miller, 1981). For each plant species on each experiment, colony count response to $\mathrm{Si}$ spray concentration was fitted to a logarithmic function, Coefficients in each function were determined by least-squares analysis using a modified Gauss-Newton regression method (SAS, 1985).

Effect of foliar-applied potassium and phosphorous. Thirtytwo cucumber plants were seeded into rockwool cubes on a greenhouse bench and watered with a low-Si $(0.05 \mathrm{~mm})$ nutrient solution. Treatments commenced when the second leaf of the cucumber plants had fully expanded and were applied to the second leaf of eight plants per treatment. Treatments included a distilled water spray ( $\mathrm{pH} 5.5)$, a $\mathrm{KOH}$ spray containing $5 \mathrm{~mm} \mathrm{~K}$ adjusted to $\mathrm{pH} 5.5$ with phosphoric acid, a phosphoric acid spray containing $5.5 \mathrm{~mm} \mathrm{P}$ adjusted to $\mathrm{pH} 5.5$ with $\mathrm{NaOH}$, and a phosphoric acid spray containing $5.5 \mathrm{~mm} \mathrm{P}$ adjusted to $\mathrm{pH} 5.5$ with $\mathrm{KOH}$. The 5 $\mathrm{mM} \mathrm{K}$ and $5.5 \mathrm{mM} \mathrm{P}$ in the sprays were equivalent to the amounts of $\mathrm{K}$ and $\mathrm{P}$ available in the $17 \mathrm{mM} \mathrm{Si}$ spray used in all experiments. Twenty-four hours after the sprays were applied, sprayed leaves were inoculated with conidia of S. fuliginea in a Fluorinert suspension of 2000 conidia $/ \mathrm{ml}$ at a rate of $0.5 \mathrm{ml} / \mathrm{leaf}$. The number of colonies per leaf was counted 1 week later. These data were analyzed using ANOVA (SAS, 1985).

Persistence of Si foliar sprays on cucumber. Cucumber plants were seeded into rockwool cubes on a greenhouse bench and watered with a low-Si $(0.05 \mathrm{~mm})$ nutrient solution. Treatments commenced when the second leaf of the cucumber plants had fully expanded. Treatments were applied to the second leaf of nine plants per treatment and included an unsprayed control and 17-mM Si sprays (pH 5.5) at 168, 96, 72, 48, and $24 \mathrm{~h}$ before inoculation. Conidia of $S$. fuliginea were inoculated onto the adaxial surface of the leaves in a Fluorinert suspension of 2000 conidia/ml at a rate of $0.5 \mathrm{ml} / \mathrm{leaf}$. The colonies per leaf were counted 1 week later. The experiment was repeated with an additional $\mathrm{Si}$ spray applied $336 \mathrm{~h}$ before inoculation. The relationship between the number of visual colonies and the delay
Table 1. The effect of Si treatments on the number of colonies of powdery mildew on cucumber, muskmelon, and zucchini squash. ${ }^{2}$

\begin{tabular}{|c|c|c|}
\hline \multirow{3}{*}{$\begin{array}{l}\text { Si applied } \\
(\mathrm{mm})\end{array}$} & \multirow[b]{3}{*}{ Treatment } & Colonies established (no.) \\
\hline & & $\begin{array}{c}\text { Zucchini } \\
\text { squash }\end{array}$ \\
\hline & & Rep 1 Rep $2 \operatorname{Rep} 1$ Rep 2 Rep 1 Rep 2 \\
\hline 0 & Control & 124 ab 353 a 59 b 71 a \\
\hline 1.7 & $\begin{array}{l}\text { Nutrient } \\
\text { solution }\end{array}$ & 69 de 65 d 14 d \\
\hline 0 & Spray & 150 a 328 a 78 a 80 a \\
\hline 1.7 & Spray & 110 bc 268 ab 48 bc 60 a \\
\hline 8.5 & Spray & $94 \mathrm{~cd} 180$ bc 35 c 28 ab \\
\hline 17.0 & Spray & 6.5 e 160 cd 13 d 15 bc 5 b $149 \mathrm{~cd}$ \\
\hline 34.0 & Spray & $13 \mathrm{c}$ \\
\hline
\end{tabular}

${ }^{2}$ The colony counts were obtained on leaf 2 on cucumber and zucchini squash and were the combined numbers on leaves 2 and 3 on muskmelon. Means separation in columns was by Dunnett's test for multiple comparisons among treatments and a control $(P<0.05)$.

period between the $\mathrm{Si}$ sprays and inoculation was analyzed using ANOVA and polynomial trend analysis (SAS, 1985).

Effects of abaxial Si application or Si removal by washing after adaxial Si application. Along with the Si-persistence experiments, leaf 2 of an additional 18 cucumber seedlings received foliar sprays of $17 \mathrm{~mm} \mathrm{Si} 24 \mathrm{~h}$ before inoculation. The second leaves of nine plants were sprayed on the abaxial surface, and the remainder were sprayed on the adaxial surface. Four hours before inoculation, leaves that received an adaxial spray were washed with water to remove the $\mathrm{Si}$ deposits. The leaves were dry at the time of inoculation. The plants were randomly arranged among plants in the Si-persistence experiments, and pathogen colonies were counted 1 week after inoculation with a Fluorinert suspension of 2000 conidia $/ \mathrm{ml}$ at a rate of $0.5 \mathrm{ml} / \mathrm{leaf}$. The experiment was repeated with an additional treatment of nine plants, each of which had the abaxial surface of leaf 2 sprayed with $\mathrm{Si} 48 \mathrm{~h}$ before inoculation.

Treatment effects on colony counts were analyzed by ANOVA. The analysis also included treated plants from the Sipersistence experiment for comparison. The analysis for the first replicate trial included the unsprayed plants and plants that received an adaxial Si spray $24 \mathrm{~h}$ before inoculation. The analysis for the second replicate trial included the unsprayed plants and plants that received an adaxial Si spray 24 or $48 \mathrm{~h}$ before inoculation. Means were separated using ANOVA and Duncan's multiple range test (SAS, 1985).

Effect of $\mathrm{Si}$ on in vitro conidial germination and germtube growth. Petri dishes containing $2 \%$ water agar amended with potassium silicate at concentrations of $0,1.7,8.5,17$, and 34 $\mathrm{mm} \mathrm{Si}$ ( $\mathrm{pH}$ adjusted to 5.5 with phosphoric acid) were inoculated with conidia of E. cichoracearum or S. fuliginea by inverting infected leaves of zucchini squash or cucumber, respectively, over petri dishes and letting the conidia settle on the agar surface. For each fungus, five petri dishes of each $\mathrm{Si}$ concentration were inoculated. The petri dishes were incubated at $20 \mathrm{C}$ in darkness for $24 \mathrm{~h}$. The germination rate of at least 100 conidia of S. fuliginea and length of germtubes of 10 randomly chosen germinated conidia of $S$. fuliginea and E. cichorucearum were determined per petri dish using a light microscope with $\times 100$ magnification. Conidia were not considered germinated unless a germtube as long as the width of the conidium was observed. Effect of $\mathrm{Si}$ concentration on germination and germ-tube growth was determined using ANOVA and polynomial trend analysis (SAS, 1985). 

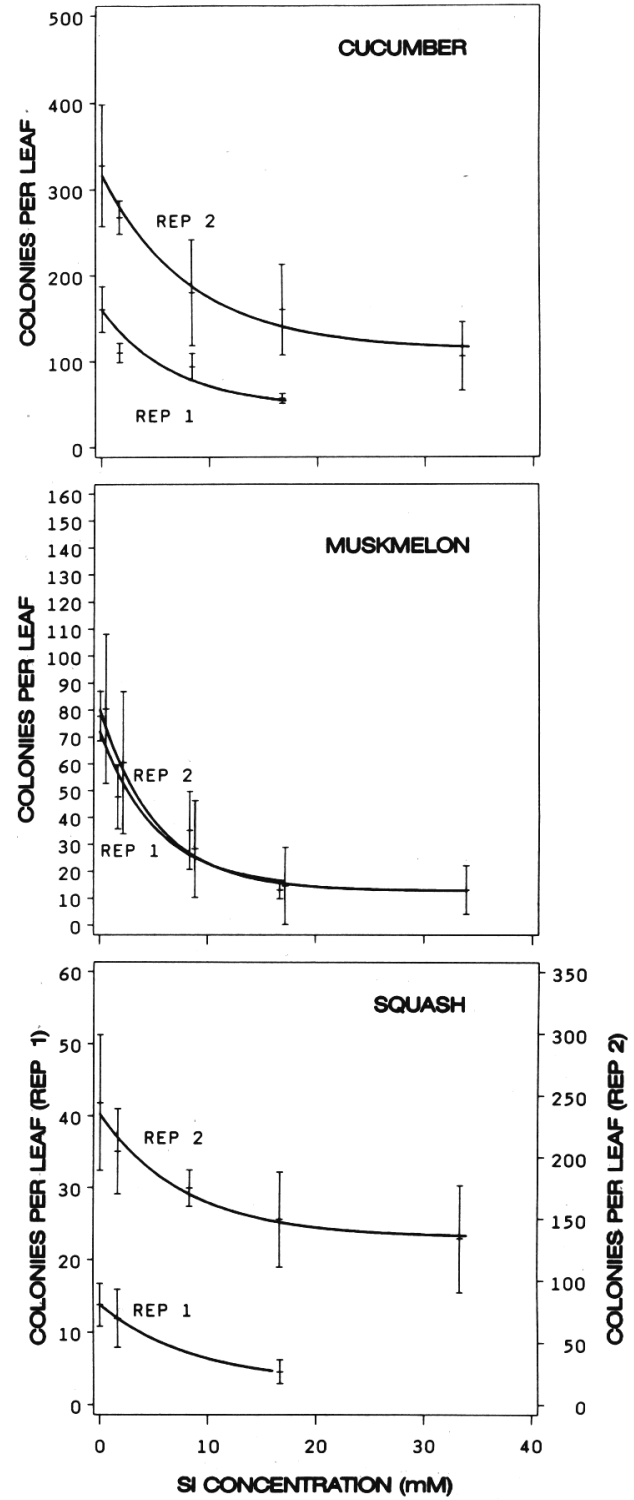

Fig. 1. Powdery mildew colony formation in response to $\mathrm{Si}$ concentration in foliar sprays. Curves fit to a logarithmic function of the form $\mathrm{y}=\mathrm{b}_{0}+\mathrm{b}_{1} \mathrm{e}^{(\mathrm{b} 2 \mathrm{x})}$. Cucumber inoculated with Sphaerotheca fuliginea, Replicate trial 1 (REP 1 ), $R^{2}=0.913, P<0.001, \mathrm{~b}_{0}=$ $112.8, \mathrm{~b},=204.6, \mathrm{~b}_{2}=-0.1213 ;$ Rep $2, R^{2}=0.954, P<$ $0.001, \mathrm{~b}_{0}=75.78, \mathrm{~b}_{1}=85.91, \mathrm{~b}_{2}=-0.503$. Muskmelon in oculated with $S$. fuliginea, Rep $1, R^{2}=0.906, P<0.005, \mathrm{~b}_{0}=$ $14.906, \mathrm{~b}_{1}=57.91, \mathrm{~b}_{2}=-0.1885 ;$ Rep $2, R^{2}=0.707, P<$ $0.07, b_{0}=12.741, b_{1}=67.39, b_{2}=-0.1879$. Zucchini squash inoculated with Erysiphe cichorucearum, Rep 1, $R^{2}=0.866, P<$ $0.30, \mathrm{~b}_{0}=3.058, \mathrm{~b}_{1}=10.756, \mathrm{~b}_{2}=-0.1180 ;$ Rep $2, R^{2}=$ $0.948, P<0.001, \mathrm{~b}_{0}=135.02, \mathrm{~b}_{1}=100.29, \mathrm{~b}_{2}=-0.1273$.

\section{Results}

Effective Si concentrations for oliar application. The nutrient solution amendment of $1.7 \mathrm{~mm} \mathrm{Si}$ and foliar applications of $\mathrm{Si}$ of $\geq 17.0 \mathrm{~mm}$ decreased the number of powdery mildew colonies on all three cucurbit species compared with the controls (Table 1). Foliar sprays with distilled water did not significantly decrease colony counts as compared with the untreated controls. Response to $\mathrm{Si}$ concentration in the foliar sprays generally fit a logarithmic function of the form $y=b_{0}+b_{1} e^{(-b 2 x)}$ (Fig. 1).

Effect of foliar-applied potassium and phosphorous. No differences $(P<0.05)$ were detected among the potassium and

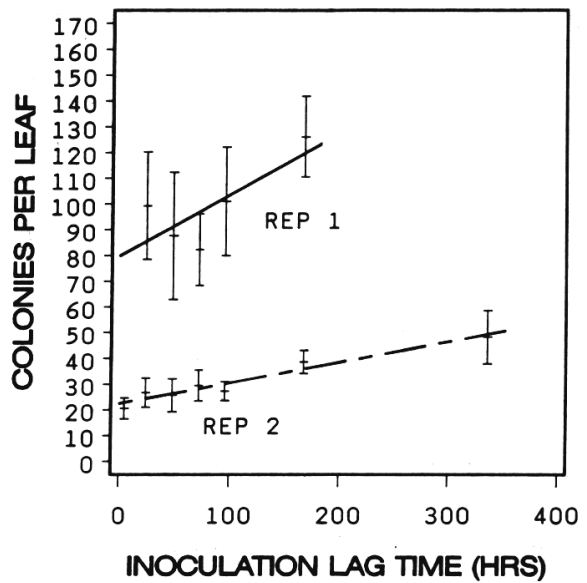

Fig. 2. The persistence of $17 \mathrm{~mm} \mathrm{Si}$ foliar sprays for reducing the number of colonies of Sphaerotheca fuliginea formed on leaves of cucumber. Lag time refers to the time interval between spray and inoculation. Replicate (REP) $1, Y=105.4-11.5(\mathrm{X})+2.1\left(\mathrm{X}^{2}\right)$, $R^{2}=0.230, P<0.01$; Replicate $2, \mathrm{Y}=22.4+1.9(\mathrm{X}), R^{2}=$ $0.500, P<0.0001$.

phosphorous treatment means, which ranged from 30 to 41 colonies per leaf (data not tabulated). This result indicates that the $\mathrm{K}$ and $\mathrm{P}$ in the potassium silicate sprays have no direct effect on powdery mildew development.

Persistence of Si foliar sprays on cucumber. The number of powdery mildew colonies that developed was directly related to the delay period between the Si spray and inoculation with $S$. fuliginea (Fig. 2). The relationship was positive and linear.

Effects of abaxial Si application or Si removal by washing after adaxial Si application. Cucumber leaves treated with $\mathrm{Si}$ sprays to the abaxial surface either 24 or $48 \mathrm{~h}$ before inoculation developed the same number of colonies as nontreated leaves (Table 2, Replicate 2). Fewer colonies developed on leaves sprayed adaxially $24 \mathrm{~h}$ before inoculation but washed $4 \mathrm{~h}$ before inoculation to remove $\mathrm{Si}$ deposits than on untreated leaves; however, counts were similar on leaves not washed but sprayed at the same time as those washed.

Effect of $\mathrm{Si}$ on in vitro conidial germination and germtube growth. The germination rate of S. fuliginea conidia ranged from $1.2 \%$ to $3.2 \%$ and was unaffected by potassium silicate in the agar media. The mean lengths of conidial germtubes of $E$. cichoracearum and S. fuliginea on the water agar unamended with potassium silicate were 26.0 and $29.5 \mu \mathrm{M}$, respectively. Potassium silicate in the agar media had no effect on germtube length in either species.

\section{Discussion}

Muskmelon and zucchini squash grown with hydroponic nutrient solutions amended with $1.7 \mathrm{~mm} \mathrm{Si}$ (in the form of potassium silicate) exhibit a substantial decrease in the number of colonies of powdery mildew that develop on inoculated leaves, as has been previously shown with cucumber (Adatia and Besford, 1986; Menzies et al., 1991a; Miyake and Takahashi, 1983a). To our knowledge, this is the first record of disease reduction due to $\mathrm{Si}$ application in these two cucurbit species, and it suggests a wider role of $\mathrm{Si}$ in the enhancement of disease resistance in the Cucurbitaceae.

Our study has also demonstrated that foliar applications of potassium silicate to cucumber, muskmelon, and zucchini squash can reduce the number of colonies of the powdery mildew pathogens. On all three hosts, foliar applications of potassium sili- 
cate at 17 or $34 \mathrm{~mm} \mathrm{Si}$ were as effective as $1.7 \mathrm{~mm} \mathrm{Si}$ root applications. Foliar applications of $17 \mathrm{~mm} \mathrm{Si}$ significantly reduced the number of colonies of $S$. fuliginea on cucumber leaves for at least $168 \mathrm{~h}$. In this respect, foliar application of $\mathrm{Si}$ appears to be superior to the application of $\mathrm{Si}$ to plants through nutrient solutions. Samuels et al. (1991b) found that, in cucumber plants treated with $1.7 \mathrm{~mm} \mathrm{Si}$ nutrient solutions, the effect of $\mathrm{Si}$ in decreasing the severity of powdery mildew on cucumber leaves was lost within $24 \mathrm{~h}$ of removing $\mathrm{Si}$ from the nutrient solutions.

The mode of action of foliar-applied potassium silicate in reducing powdery mildew colony numbers was not determined. However, it appears that $\mathrm{Si}$ is the active ingredient of the foliar spray, since $\mathrm{K}$ and $\mathrm{PO}_{4}$ sprays equivalent in concentration to that in the Si spray did not reduce disease development. This result does not preclude the possibility that $\mathrm{K}$ or $\mathrm{PO}_{4}$ may be involved in the activity of $\mathrm{Si}$ in decreasing mildew development.

Light microscope and scanning electron microscope studies have indicated that $\mathrm{Si}$ applied in nutrient solutions may enhance the natural resistance of cucumber to S. fuliginea (Menzies et al., 1991b; Samuels et al., 1991b). Both Si and phenolic compounds have been observed to accumulate around sites of penetration by the powdery mildew fungus (Menzies et al., 1991b; Samuels et al., 1991a). Although similar studies have not been conducted on Si-sprayed cucumber leaves, $\mathrm{Si}$ possibly is absorbed into the leaves where it acts in a manner similar to that of $\mathrm{Si}$ supplied through root absorption. This possibility is supported by the observation that $\mathrm{Si}$-sprayed leaves that were washed to remove surface $\mathrm{Si} 4$ to $5 \mathrm{~h}$ before inoculation had significantly fewer colonies than nonsprayed leaves. Si absorbed before the wash may have been sufficient to reduce the establishment of pathogen colonies by enhancing resistance. The duration of this enhancement by leaf absorption of Si is probably not long. Samuels et al. (1991b) found that enhanced powdery mildew resistance in cucumber leaves on plants treated with $1.7 \mathrm{~mm}$ nutrient solutions lasted only $24 \mathrm{~h}$ after removal of $\mathrm{Si}$ from the nutrient solution.

Also, deposits of $\mathrm{Si}$ on the leaf surface may restrict fungal development or penetration. However, conidial germination of $S$. fuliginea and growth of the germtubes of conidia of $S$. fuliginea and E. cichoracearum were unaffected by potassium silicate in the agar media. P.B. and J.M. (unpublished data) have examined the effect of a potassium silicate amendment to water agar on conidia of Uncinula necator (Schwein.) Burrill [powdery mildew of grape (Vitis vinifera L.)]. Germination of conidia and germtube growth of $U$. necator after $24 \mathrm{~h}$ were enhanced by the presence of potassium silicate. These in vitro tests suggest that potassium silicate is not detrimental to initial pathogen

Table 2. Comparison of adaxial and abaxial application, and postspray washing of $17 \mathrm{~mm} \mathrm{Si}$ sprays on the number of colonies of Sphaerotheca fuliginea on cucumber leaves. ${ }^{\mathrm{z}}$

\begin{tabular}{llll}
\hline \hline \multirow{2}{*}{$\begin{array}{l}\text { Delay between Si } \\
\text { spray and } \\
\text { inoculation }(\mathrm{h})\end{array}$} & $\begin{array}{c}\text { Leaf } \\
\text { surface } \\
\text { sprayed }\end{array}$ & & \multicolumn{2}{c}{ Colony } & no. \\
\cline { 2 - 5 } 24 & Adaxial & $104 \mathrm{c}$ & $26.7 \mathrm{~b}$ \\
48 & Adaxial & & $25.7 \mathrm{~b}$ \\
24 & Abaxial & $157 \mathrm{ab}$ & $51.9 \mathrm{a}$ \\
48 & Abaxial & & $49.4 \mathrm{a}$ \\
24, washed off & Adaxial & $135 \mathrm{bc}$ & $24.9 \mathrm{~b}$ \\
Control (untreated) & Adaxial & $187 \mathrm{a}$ & $48.5 \mathrm{a}$ \\
\hline
\end{tabular}

${ }^{2}$ Means separation in columns by Duncan's multiple range test $(P<$ 0.0002) (SAS, 1985). development and may even promote early development of some pathogens. But the coating of potassium silicate crystals that forms on the leaf surface after the sprays dry may act as a physical barrier to pathogen penetration of the epidermis.

Failure to reduce the number of colonies formed on leaves whose abaxial leaf surfaces were sprayed with a $17 \mathrm{~mm} \mathrm{Si}$ solution may have been due to an inability of the abaxial leaf surface to absorb Si. Alternatively, $\mathrm{Si}$ absorbed through the abaxial leaf surface may not move very far in the leaf before becoming immobilized. This immobility may reduce the efficacy of potassium silicate sprays against natural infections of powdery mildew of cucurbits, as these pathogens can infect both the abaxial, and adaxial surfaces of leaves.

Our results suggest that spray applications of potassium silicate may be used to control powdery mildew in the field. Earlier work on hydroponic nutrient solution amendment with potassium silicate (Menzies et al., 1991a; Samuels et al., 1991b) has resulted in commercial application to greenhouse cucumbers. Previously reported applications of $\mathrm{Si}$ in the field have been to soils at rates ranging from $250 \mathrm{~kg}$ sodium silicate/ha to $4500 \mathrm{~kg}$ potassium silicate/ha (Leusch and Buchenauer, 1989; Mathai et al., 1978; Miyake and Takahashi, 1983b). Our results indicate that effective foliar applications would be at much lower rates.

\section{Literature Cited}

Adatia, M.H. and R.T. Besford. 1986. The effects of silicon in cucumber plants grown in recirculating nutrient solution. Ann. Bot. 58:343-351.

Aleshin, N.E., E.R. Avakyan, S.A. Dyakunchak, E.P. Aleshkin, V.P. Baryshok, and M.G. Voronkov. 1986. Role of silicon in resistance of rice to blast. Dokl. Akad. Nauk SSSR 291 (2):499-502.

Boesewinkel, H.J. 1980. The morphology of the imperfect states of powdery mildews (Erysiphaceae). Bot. Rev. 46:167-224.

Jiang, D., R.J. Zeyen, and V. Russo. 1989. Silicon enhances resistance of barley to powdery mildew. Phytopathology 79:1198. (Abstr.)

Leusch, H.J. and H. Buchenauer. 1989. Effect of soil treatments with silica; rich lime fertilizers and sodium trisilicate on the incidence of wheat by $\mathrm{Er}$ ysiphe graminis and Septoria nodorum depending on the form of N-fertilizer. Z. Pflanzenkr. Pflanzensshutz 96(2):154-172.

Mathai, G., P.V. Paily, and M.R. Menon. 1978. Effect of fungicides and silica in the control of sheath blight disease of rice caused by Corticum sasakii (Shiriai). Agr. Res. J. Kerala 19(1):79-83.

Menzies, J.G., D.L. Ehret, A.D.M. Glass, T. Helmer, C.Koch, and F. Seywerd. 1991a. The effects of soluble sillicon on the parasitic fitness of Sphaerotheca fuliginea on Cucumis sativus. Phytopathology 81:84-88.

Menzies, J.G., D.L. Ehret, A.D.M. Glass, and A.L. Samuels. 1991b. The influence of silicon on the cytological interactions between Sphaerotheca fuliginea and Cucumis sativus. Physiol. \& Mol. Plant Pathol. 39:403-414.

Menzies, J.G. and B.H. MacNeill, i986. Asexual recombination in Erysiphe graminis f. sp. tritici. Can. J. Plant Pathol. 8:400-404.

Miller, R.G. 1981: Simultaneous statistical inference. Second ed., SpringerVerlag, New York. p. 76-78.

Miyake, Y. and E. Takahashi. 1983a. Effect of silicon on the growth of solutioncultured cucumber plants. Soil Sci. Plant Nutr. 29:71-83.

Miyake, Y. and E. Takahashi. 1983b. Effect of silicon on the growth of cucumber plant in soil culture. Soil Sci. Plant Nutr. 29:463-471.

Reeser, PI, D.J. Hagedorn, and D.I. Rouse. 1983. Quantitative inoculations with Erysiphe pfsi to assess variation of infection efficiency on peas. Phytopathology 73:1238-1240.

SAS Institute, Inc. 1985. SAS user's guide; Statistics. SAS Institute, Inc., Cary, N.C.

Samuels, A.L., A.D.M. Glass, D.L. Ehret, and J.G. Menzies. 1991a. Distribution of silicon in cucumber leaves during infection by powdery mildew fungus (Sphaerotheca fuliginea). Can. J. Bot. 69:140-146.

Samuels, AL., A.D.M. Glass, D.L. Ehret, and J.G. Menzies. 1991b. Mobility and deposition of silicon in cucumber plants. Plant Cell \& Environ. 14:485492.

Volk, R.J., R.P., Kahn, and R.L. Weintraub. 1958. Silicon content of the rice plant as a factor influencing its resistance to infection by the blast fungus, Piricularia oryzae. Phytopathology 48:179-184. 